\title{
Customer preference based optimization in selecting product/service variety
}

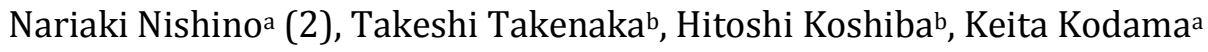 \\ a Department of Technology Management for Innovation, School of Engineering, The University of Tokyo, Tokyo, Japan \\ ${ }^{b}$ Center for Service Engineering, National Institute of Advanced Industrial Science and Technology, Tokyo, Japan
}

The breadth of customer choice of products and services has increased dramatically. Consequently, both manufacturing and services have adopted elaborate variety management to satisfy various customer needs while maintaining business profitability. Our study presents a formulation of variety selection problems considering customer preferences by the introduction of preference order from economic theory. Using Frequent Shopper Program data of a large shopping mall in Japan, our proposed framework is applied to the optimization of tenant-mix problems as a case study of service variety selection. Results demonstrate how an optimized variety of shops can satisfy various customer preferences at a reasonable profit level.

Optimization, Decision making, Service engineering

\section{Introduction}

Product/service variety management is an increasingly important issue in manufacturing and service industries along with the rapid globalization and intensive use of information in business activities [1]. In the manufacturing context, mass customization and personalization have been emphasized to accommodate the diversification of customer needs and rapid alteration of social trends while maintaining mass-production efficiency [2, 3]. Moreover, because customer information and customer participation are expected to play important roles for mass customization and personalization, possible design methodologies such as Quality Function Deployment considering user demands have been introduced for design for variety [4].

In service industries, which have points of customer contact, product/service variety management is crucial for daily business operations. Retail store managers must select products and services based on their estimation of customer needs and satisfaction within many limitations imposed by store size, timing, and operating costs. In the supermarket industry, for example, category management [5] is a key issue for their daily operations: it entails variety planning, which optimizes the combination of different category products, and assortment planning, which optimizes the selection of products of different types in the same category. However, it depends on manager experience: no wellestablished tool exists [6]. Consequently, managers must specifically examine customer behaviours using available data acquired through services. Although customer purchase data are a major resource showing customer behaviours for service providers to ascertain customer needs, such data are insufficient for elucidating customer decision-making processes including their motivations, lifestyles, price perceptions, or satisfaction with products and services after use.

Customer relationship management (CRM) is an increasingly important concern for the retail industry along with the popularization of frequent shopper programs (FSP) and loyalty programs [7] using membership cards. In actual loyalty programs, the main purpose of retail shops is to cultivate loyal customers using various incentives according to customer types categorized based on recency, frequency, and monetary (RFM) factors. Many retail outlets such as supermarkets and shopping malls have introduced loyalty programs to ascertain customer behaviors and needs. However, to clarify the true needs of various customers, it is usually difficult to tap into a huge amount of customer data having sparseness because of the lack of useful technologies and analysis of costs. In the field of service engineering, the authors specifically examine customer heterogeneity, having developed classification and modeling methodologies of customers considering customer preferences and lifestyles using large-scale purchase data [8]. Takenaka et al. classified shopping mall customers and tenants into some latent classes using probabilistic latent semantic indexing (PLSI) with 150,000 member customer purchase log data for 220 tenants [9], particularly addressing the combination of shops purchased by customers. Results show that customers' daily behaviors and responses to sales promotions were clarified by those classifications. An important challenge of a shopping mall owner is the so-called tenant mix problem to maximize total profits of a shopping mall [10]. Nevertheless, that is an intrinsically difficult problem. It is insufficient to select tenants solely according to sales revenues of tenants; shopping malls should consider customer motivations and satisfaction, and should seek to develop a long-term relationship with neighbourhood customers.

The field of economics has increasingly addressed issues of customer motivation and satisfaction over the years. In economics, such an issue is modeled theoretically simply as a preference order, as explained along with other details in section 2. Herein, developing the preference order idea, we propose an optimization methodology of product/service variety that can satisfy both total profitability and heterogeneous customer preferences. Then, the method's effectiveness is demonstrated using actual customer data of a retail business.

\section{Formulating product/service variety selection as an optimization problem}

\subsection{Basic framework}

This study examines the selection of product/service variety selection by which a producer/service provider selects a 
combination of products/services from alternatives. For example, a producer might decide a product family or lineup of products in manufacturing.

Possible alternatives of products/services that a producer/service provider confronts are defined as a set, $S=\left\{s_{1}, S_{2}, \cdots, s_{n}\right\}$, where $S$ is a finite set and where each element denotes one kind that is not identical to any other in $S$. In addition, $n$ stands for the number of all alternatives. Thereby, product/service variety selection is described simply as a problem by which the optimal subset $S^{*} \subset S$ should be selected from $S$.

Customer preference is described based on the theory of consumer choice in economics as follows.

$$
s_{3} \succ s_{1} \succ s_{2} \cdots
$$

Therein, $\succ$ stands for preference order and is an economics application of binary relation in mathematics. The formula above means that, for a person with $\succ, S_{3}$ is preferred to $S_{1}, S_{1}$ is preferred to $S_{2}, \ldots$ and so on. Preference order generally differs among customers. Accordingly, if defining a customer set as $N$, then the preference order of consumer $i \in N$ is described as $\succ_{i}$. It can be differentiated from others by the index.

\subsection{Introducing a hierarchy structure of customer preference}

Customers have different preferences. Therefore, under the formulation presented above, the number of customer preference alternatives will increase exponentially as the number of elements in $S$ increases. Because the number of combination of alternatives can be expressed as $n$ ! in our framework, computational explosion might arise as the variety of product/service increases. As a countermeasure, a two-level hierarchy over customer preferences is introduced as shown in Figure 1. The higher layer stands for a group such as category or genre; the lower layer stands for the product/service variety. The figure shows that one node at the higher layer comprises several nodes at the lower layer.

Based on the hierarchy, the following rules are assumed in terms of customer preference description.

- Rule 1: Each customer has a preference over groups, which takes priority over variety at the lower layer. If a certain group is preferred to another group, all products/services in the preferred group are always preferred to any one in the other group.

- Rule 2: Each customer has a preference over products/services in each group. When any two are included in the same group, the two are distinguishable based on preference.

These rules can be described mathematically as follows. Groups are defined as a family of sets $G=\{T \mid T \subset S\}$, where the following constraints hold:

$$
\bigcup_{T \in G} T=S \text { and } \bigcap_{T \in G} T=\varnothing .
$$

Then, defining customer i's preference order over groups as $\succ_{i}^{G}$, each customer preference is described as a tuple of $\left(\succ_{i}^{G}, \succ_{i}\right)$. The

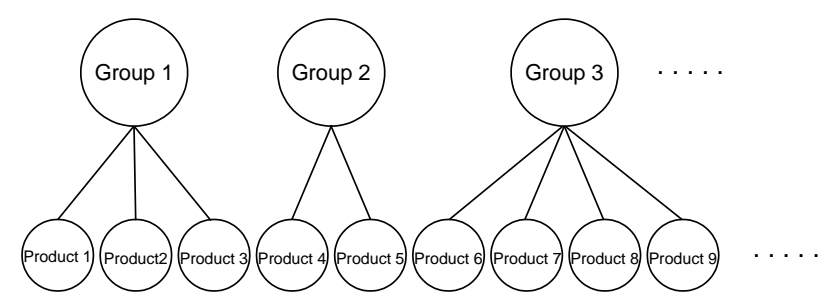

Figure 1. Two-level hierarchy. first element expresses a preference order over groups. The second element expresses a preference order over products/services. Herein, from the hierarchy rules, the following condition must be satisfied.

$$
\begin{aligned}
& \text { When customer } i \text { has a preference of }\left(\succ_{i}^{G}, \succ_{i}\right) \text {, if } \\
& T \succ_{i}^{G} T^{\prime} \text { for } \forall T, T^{\prime} \in G \text {, then } t \succ_{i} t^{\prime} \text { must hold for } \\
& \forall t \in T \text { and } \forall t^{\prime} \in T^{\prime} .
\end{aligned}
$$

By those arrangements, the calculation amount can be reduced.

\subsection{Criteria for preference-based optimization}

One can consider the optimum combination of product/service variety based on the preference order framework described in previous subsections. Based on the idea of Pareto optimality, the study defines the optimal solution as a state in which no customer preference level can be improved without decreasing any other's preference level. As described in subsection 2.1, a feasible solution in this optimization problem is described as a subset of $S$. Consequently, the purpose is to find the best $S^{*} \subset S$ based on Pareto optimality in customer preference.

When one feasible solution $S^{*}$ is selected, the remainder set is defined as $S^{c} \equiv S \backslash S^{*}$. We specifically examine a certain customer $i$ who has a preference of $\left(\succ_{i}^{G}, \succ_{i}\right)$ and compare $S^{*}$ with $S^{c}$ based on that preference. Focusing on an element, $s \in S^{*}$, we compare $s$ with each element in $S^{c}$ and collect elements which are preferable to $s$ (see Figure 2). In accordance with the idea of the hierarchy structure explained in subsection 2.2 , the following two sets are defined.

$$
\begin{aligned}
& D_{i}^{G}(s)=\left\{a \mid \mathrm{T}(a) \succ_{i}^{G} \mathrm{~T}(s), a \notin \mathrm{T}(s), a \in S^{c}\right\} \\
& D_{i}(s)=\left\{a \mid a \succ_{i} s, a \in \mathrm{T}(s), a \in S^{c}\right\}
\end{aligned}
$$

Therein, $\mathrm{T}$ is a mapping such that $\mathrm{T}: S \rightarrow G$ and $\mathrm{T}(s)$ signifies the group that contains $s . D_{i}^{G}(s)$ and $D_{i}(s)$ can be regarded as sets that contain elements which should be chosen for customer $i$. Then, taking their cardinality, $\left|D_{i}^{G}(s)\right|$ and $\left|D_{i}(s)\right|$, the respective numbers can be regarded as a sort of criterion of a product/service $s$ for customer i. For $\left|D_{i}^{G}(s)\right|=0$ and $\left|D_{i}(s)\right|=0$, the customer's preference is satisfied completely. Now, taking all elements in $S^{*}$ and all customers, the following criteria are obtained.

$$
\begin{aligned}
& \text { Inter-group criterion: } c^{\text {Inter }}\left(S^{*}\right)=\sum_{i \in N} \sum_{s \in S^{*}}\left|D_{i}^{G}(s)\right| \\
& \text { Intra-group criterion: } c^{\text {Intra }}\left(S^{*}\right)=\sum_{i \in N} \sum_{s \in S^{*}}\left|D_{i}(s)\right|
\end{aligned}
$$

Herein, when both values are 0 , the best state is indicated. However, realizing a value of 0 is difficult as long as preferences differ among customers. By the definition of the hierarchy, the inter-group criterion takes priority over the intra-group criterion. Therefore, optimization is accomplished based on the inter-group criterion. Then if the values in the inter-group criterion are the

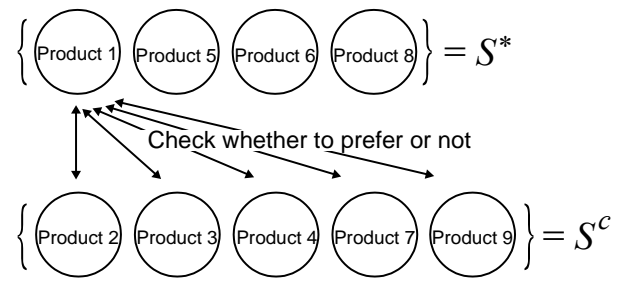

Figure 2. Check preference order for each element between $S^{*}$ and $S^{c}$. 
same, the intra-group criterion is used for judgment. The optimization problem in our study is

$$
\min _{S^{*} \subset S} c^{\text {Inter }}\left(S^{*}\right) \text {. }
$$

Herein, for multiple solutions in minimizing the inter-group criterion, the solution is obtained from

$$
\min _{S^{*} \in \bar{S}} c^{\text {Intra }}\left(S^{*}\right), \quad \bar{S}=\left\{\hat{S} \mid \hat{S}=\underset{S^{\prime} \subset S}{\arg \min } c^{\text {Inter }}\left(S^{\prime}\right)\right\},
$$

where $\bar{S}$ stands for a family of sets that minimize the inter-group criterion. The solution attains a state of Pareto efficiency.

\section{Elucidation of preference-based optimization mechanism and characteristics using an actual small sample}

\subsection{Targeted sample case for elucidation}

To elucidate the mechanism of the proposed preference-based framework, we next consider a simple example of tenant mix problems using a few actual data. We address a problem in which appropriate tenants in a large shopping mall are selected from many different shops. With the cooperation of a Japanese company that manages a large shopping mall, we obtained several managerial data. Among the data, we emphasize nine actual shops as shown in Table 1 . We use an optimization problem of selecting the five optimal tenants from the nine shops based on customer preference.

\subsection{Extracting customer preferences}

The large shopping mall operates a loyalty program. For that reason, the data include respective customers' purchase histories in detail. We use repeated customer visits to a shop as representative of customer preferences. The repetitions here represent how many times each customer uses a certain shop. Accordingly, it can be inferred that if the number for a certain shop is large, then its customers would prefer the shop. It is independent of how much a customer has spent at the shop.

As a hierarchy of customer preference presented in subsection 2.2 , we consider three groups as constituting the higher layer. The group categorization for the nine shops is presented at the right column in Table 1: Group A includes shops for ladies; Group B includes food and grocery shops; and Group C includes shops for families or multiple generations.

For analysis of the mechanism of the proposed preferencebased framework, we next consider three simple distributions of customer preferences as presented below.

Table 1

Nine targeted shops

\begin{tabular}{|l|l|r|c|}
\hline Shop name & Description of shop & $\begin{array}{l}\text { Average } \\
\text { sales/day }\end{array}$ & Group \\
\hline Shop No. 1 & Cosmetic shop for women & 0.51 & $\mathrm{~A}$ \\
\hline Shop No. 2 & $\begin{array}{l}\text { Fashion boutique for young } \\
\text { people }\end{array}$ & 1.23 & $\mathrm{~A}$ \\
\hline Shop No. 3 & $\begin{array}{l}\text { Fashion boutique for women } \\
\text { in their 30-40s }\end{array}$ & 0.38 & $\mathrm{~A}$ \\
\hline Shop No. 4 & $\begin{array}{l}\text { Import food and luxury } \\
\text { ingredient shop }\end{array}$ & 0.72 & $\mathrm{~B}$ \\
\hline Shop No. 5 & Organic grocery & 0.53 & $\mathrm{~B}$ \\
\hline Shop No. 6 & Low-price snack shop & 0.47 & $\mathrm{~B}$ \\
\hline Shop No. 7 & Electronics store & 3.85 & $\mathrm{C}$ \\
\hline Shop No. 8 & Specialized shop for pets & 1.10 & $\mathrm{C}$ \\
\hline Shop No. 9 & Camera store & 0.21 & $\mathrm{C}$ \\
\hline
\end{tabular}

Note: Because of non-disclosure agreements, shops are presented under anonymity. Figures in the average sales column show the ratio of the average of individual shops to the average of all nine shops.
Table 2

Scenario 1 result

\begin{tabular}{|c|l|r|r|r|}
\hline Rank & Five selected shops & \multicolumn{1}{|l|}{$\begin{array}{l}\text { Inter-group } \\
\text { criterion }\end{array}$} & $\begin{array}{l}\text { Intra-group } \\
\text { criterion }\end{array}$ & \multicolumn{1}{l|}{ Sales } \\
\hline 1 & Nos. $2,4,5,7,8$ & 29 & 7 & 1.49 \\
\hline 2 & Nos. $2,4,6,7,8$ & 29 & 8 & 1.47 \\
\hline 3 & Nos. $2,5,6,7,8$ & 29 & 9 & 1.44 \\
\hline 4 & Nos. $1,4,5,7,8$ & 29 & 10 & 1.34 \\
\hline 4 & Nos. $3,4,5,7,8$ & 29 & 10 & 1.32 \\
\hline
\end{tabular}

Table 3

Scenario 2 result

\begin{tabular}{|c|l|r|r|r|}
\hline Rank & Five selected shops & \multicolumn{1}{|l|}{$\begin{array}{l}\text { Inter-group } \\
\text { criterion }\end{array}$} & $\begin{array}{l}\text { Intra-group } \\
\text { criterion }\end{array}$ & \multicolumn{1}{l|}{ Sales } \\
\hline 1 & Nos. $3,4,6,7,8$ & 32 & 9 & 1.30 \\
\hline 2 & Nos. $1,4,6,7,8$ & 32 & 10 & 1.33 \\
\hline 2 & Nos. $2,4,6,7,8$ & 32 & 10 & 1.47 \\
\hline 4 & Nos. $3,4,6,8,9$ & 32 & 11 & 0.56 \\
\hline 5 & Nos. $1,4,6,8,9$ & 32 & 12 & 0.60 \\
\hline
\end{tabular}

Table 4

Scenario 3 result

\begin{tabular}{|c|l|r|r|r|}
\hline Rank & Five selected shops & \multicolumn{1}{|l|}{$\begin{array}{l}\text { Inter-group } \\
\text { criterion }\end{array}$} & $\begin{array}{l}\text { Intra-group } \\
\text { criterion }\end{array}$ & \multicolumn{1}{l|}{ Sales } \\
\hline 1 & Nos. $1,3,4,6,7$ & 29 & 6 & 1.19 \\
\hline 2 & Nos. $1,3,4,6,9$ & 29 & 7 & 0.46 \\
\hline 3 & Nos. 1, 2, 4, 6, 7 & 29 & 10 & 1.19 \\
\hline 3 & Nos. 1, 3, 5, 6, 7 & 29 & 10 & 1.15 \\
\hline 5 & Nos. 1, 2, 4, 6, 9 & 29 & 11 & 0.63 \\
\hline
\end{tabular}

- Scenario 1: Repetitions and sales have the same trend.

- Scenario 2: Each customer uses all shops evenly.

- Scenario 3: Repetitions and sales have an opposite trend. For simplicity, those three distributions respectively include data for only five customers, as determined by selecting respective customers' data intentionally to satisfy the three distributions.

\subsection{Optimization results in three scenarios}

Tables 2-4 present the results. Each table shows the top five optimum solutions. In this case, the criteria theoretically extend from 0 through 100 for the inter-group and from 0 through 20 for the intra-group. In the tables, the sales column stands for the total sales of five selected shops, each of which is expressed as the ratio of the corresponding five shops' sales in the same manner as Table 1. Table 2 shows that the solutions obtained using the proposed preference-based optimization can achieve sales maximization. Fundamentally, correspondence exists between preference order and sales in this scenario. Shop No. 7, which has the best sales, is included in all of the top five solutions. Shops of various kinds are selected through the top five solutions in Table 3 . The sales performance is dispersed over a wide range. Table 4 presents a different tendency from those of the other two scenarios. In this scenario, Shop No. 1 is invariably included in the top five. The shop's sales are not so high, but most customers in this scenario prefer this shop. Therefore, the shop is included but the total sales present poor performance. This case is a typical one in which many customers are satisfied but shops suffer from low profitability.

As scenario 3 shows, the proposed optimization method depends strongly on the distribution of customer preference. Therefore, good sales performance of its solution is not assured. However, if customers prefer some shops, then they generally have a positive correlation with sales. Our proposed method is expected to realize a reasonable profit level, simultaneously satisfying customer preference. The next section presents an investigation of a case study to assess the proposed method in an actual business situation. 


\section{Case study: application to a large shopping mall in Japan}

The study directly applies the proposed method to a case of a large shopping mall in Japan: its 200 tenants share a total floor area greater than $25,000 \mathrm{~m}^{2}$. The customer purchase history data were obtained during Apr. 2011 - Mar. 2012. The customers providing the data were 37,099 . They were customers who visited the mall more than once a month. The shops were limited to those reporting the 50 highest sales revenues. Given those data, we can consider replacing some shops with new shops. Determining the optimum combination of stores as the problem, we seek to retain only some currently existing shops.

The repeat rate below is adopted as an indicator of customer preference.

$$
\text { Repeat rate }=\frac{\text { The total times of visiting a store }}{\text { The total days of visiting the mall }}
$$

The hierarchy is determined based on the category obtained using the probabilistic latent semantic indexing model (PLSI) [9], finally separating all shops into the following five categories:

- Group 1: Shops that customers residing near the mall most often use, providing items that are mainly daily necessities.

- Group 2: Shops mainly for young women, selling fashion items, household goods, and sweets.

- Group 3: Shops mainly for men.

- Group 4: Shops mainly for elderly women.

- Group 5: Shops selling accessories and goods for pets. From those data, the average repeat rate for each group is calculated and used as a preference order at the higher level. Similarly, each preference order is set from the repeat rate for respective shops in each group.

Genetic algorithms are used for preference-based optimization, in which an individual is modeled as a combination of shops and its fitness is the inter-group and intra-group criteria. The number of individuals is 10 . Algorithms are repeated until the 1000th generation.

Results are presented in Figure 3 and Table 5. Computations are done under several settings by changing the number of retained shops from 10 to 40. For comparison, the solutions derived based on the sales are presented. The best $n$ shops in sales are simply selected. Figure 3 presents results for 10 shops. Bold-faced shop names denote shops included in both solutions. In the figure, different shops are selected in part. However, the top three shops in sales are also included in the solution using the preferencebased method. Table 5 shows that the proposed method does not realize sales-maximization but can succeed in a reasonable sales level. The sales value approaches that of sales-based selection, especially when the number of retained shops is greater. In general, the retained shops are not so few in reality. Therefore our proposed method shows effectiveness in terms of practical applications.

\section{Discussion and Conclusions}

Although the case study is presented as a problem of selecting shops in the mall, our proposed method can be applicable to broader issues in products/services variety management. For example, in case of item selection in a shop, it would be applicable just by finding customers' preference order about respective items, using point-of-sale data or a sort of marketing methods. In the same manner, it is applicable to an issue of product family selection as well. However, because our approach only considers customers' preference, it does not guarantee profit-maximization. Therefore, it would be necessary to develop another new method to quantify the relation between preference and profit levels as a future work.

\begin{tabular}{|c|c|c|}
\hline Proposed method & \multirow{2}{*}{ High } & Sales-based selection \\
\hline Bookstore A & & Electric shop N \\
\hline Café S & \multirow{2}{*}{$\underset{\underline{\Phi}}{\bar{\Phi}}$} & Bookstore A \\
\hline Café C & & Department store $\mathrm{M}$ \\
\hline Restaurant $\mathrm{T}$ & \multirow{2}{*}{$\begin{array}{l}0 \\
0 \\
\Phi \\
\Phi \\
\end{array}$} & Pet shop K \\
\hline Bakery B & & Fashion shop Z \\
\hline Grocery K & \multirow{4}{*}{$\frac{\frac{\Phi}{2}}{\frac{\omega}{2}}$} & Shoe shop A \\
\hline Grocery O & & Brand shop A \\
\hline Café $P$ & & Grocery K \\
\hline Electric shop $\mathrm{N}$ & & Daily necessity store $F$ \\
\hline Department store M & $\begin{array}{l}\vee \\
\text { Low }\end{array}$ & Ladies fashion shop $\mathrm{H}$ \\
\hline
\end{tabular}

Figure 3. Solutions obtained using the proposed method and sales-

Table 5

based selection.

Sales achieved using the proposed method and sales-based selection

\begin{tabular}{|l|c|c|c|c|}
\hline Number of retained shops & $\mathbf{1 0}$ & $\mathbf{2 0}$ & $\mathbf{3 0}$ & $\mathbf{4 0}$ \\
\hline Proposed method & 2.04 & 1.27 & 1.10 & 1.07 \\
\hline Sales-based selection & 2.80 & 1.83 & 1.42 & 1.16 \\
\hline
\end{tabular}

Note: These figures are ratios of sales under the assumption that the average sales value of all shops is 1 .

Economics usually deal with preference order theoretically. In reality, however, customer preferences widely differ among individuals and accordingly it causes combinatorial explosion as the number of varieties increases. By introduction of a hierarchy in preference order, our method overcomes the problem of combinatorial explosion and provides feasible solutions. This is an advantage of the proposed method.

Our study first formulates product/service variety selection as an optimization problem. Second, the small example case is considered to elucidate the preference-based optimization mechanism. Third, its effectiveness is demonstrated using a case study of a large shopping mall. The proposed method attains not only preference optimization, but also a reasonable sales level. The proposed method is anticipated for application to broader issues such as product customization and personalization.

\section{Acknowledgements}

This research was supported by Service Science, Solutions and Foundation Integrated Research Program (S3FIRE), Research Institute of Science and Technology for Society (RISTEX), Japan Science and Technology Agency (JST).

\section{References}

[1] El Maraghy H, Schuh G, El Maraghy W, Piller F, Schönsleben p, Tseng M, Bernard A. (2013) Product variety management, CIRP Annals - Manufacturing Technology 62(2): 629-652.

[2] Pine J, Davis S (1993) Mass Customization: The New Frontier in Business Competition, Harvard Business School Press, Boston.

[3] Tseng MM, Piller FT (2003) The Customer Centric Enterprise: Advances in Mass Customization and Personalization, Springer, Berlin/New York.

[4] Li B, WuF (2011) Analyzing the Variety of Customer Needs for Product Family Design by Integrating Conjoint Analysis And Quality Function Deployment. second Int. Conf. on Digital Manufacturing and Automation, ICDMA 2011, Zhangjiajie, China.

[5] Hübner AH, Kuhn H (2012) Retail category management: State-of-the-art review of quantitative research and software applications in assortment and shelf space management, Omega 40:199-209.

[6] Mantrala MK, Levy M, Kahn BE, Fox EJ, Gaidarev P, Dankworth B, Shah D (2009) Why is assortment planning so difficult for retailers? A framework and research agenda, Journal of Retailing 85(1):71-83.

[7]Kumar V, Denish S (2004) Building \& Sustaining Profitable Customer Loyalty for the 21st Century, Journal of Retailing 80 (4):317-330.

[8]Takenaka T, Koshiba H, Motomura Y, Ueda K (2013), Product/service variety strategy considering mixed distribution of human lifestyles, CIRP Annals Manufacturing Technology, 62(1), 463-466.

[9] Takenaka, T, Koshiba, H, Takayama K, Kojima M, Motomura Y, Takaku M, Sasaki T (2013) Modeling customer behavior in a shopping mall: tenant variety and customer type, Proc. first International conference on Serviceology (ICServ2013)

[10]Yuo, T ,Crosby N, Lizieri C, McCann P (2004), Tenant Mix Variety in Regional Shopping Centres: Some UK Empirical Analyses, in Real Estate \& Planning Working Papers (rep-wp2004-02), Henley Business School, Reading University. 